Document downloaded from:

http://hdl.handle.net/10251/37915

This paper must be cited as:

Fombuena, V.; Sanchez-Nacher, L.; Samper, m.D.; Juárez Varón, D.; Balart, R. (2013). Study of the Properties of Thermoset Materials Derived from Epoxidized Soybean Oil and Protein Fillers. Journal of the American Oil Chemists' Society. 90:449-457. doi:10.1007/s11746-012-2171-2.

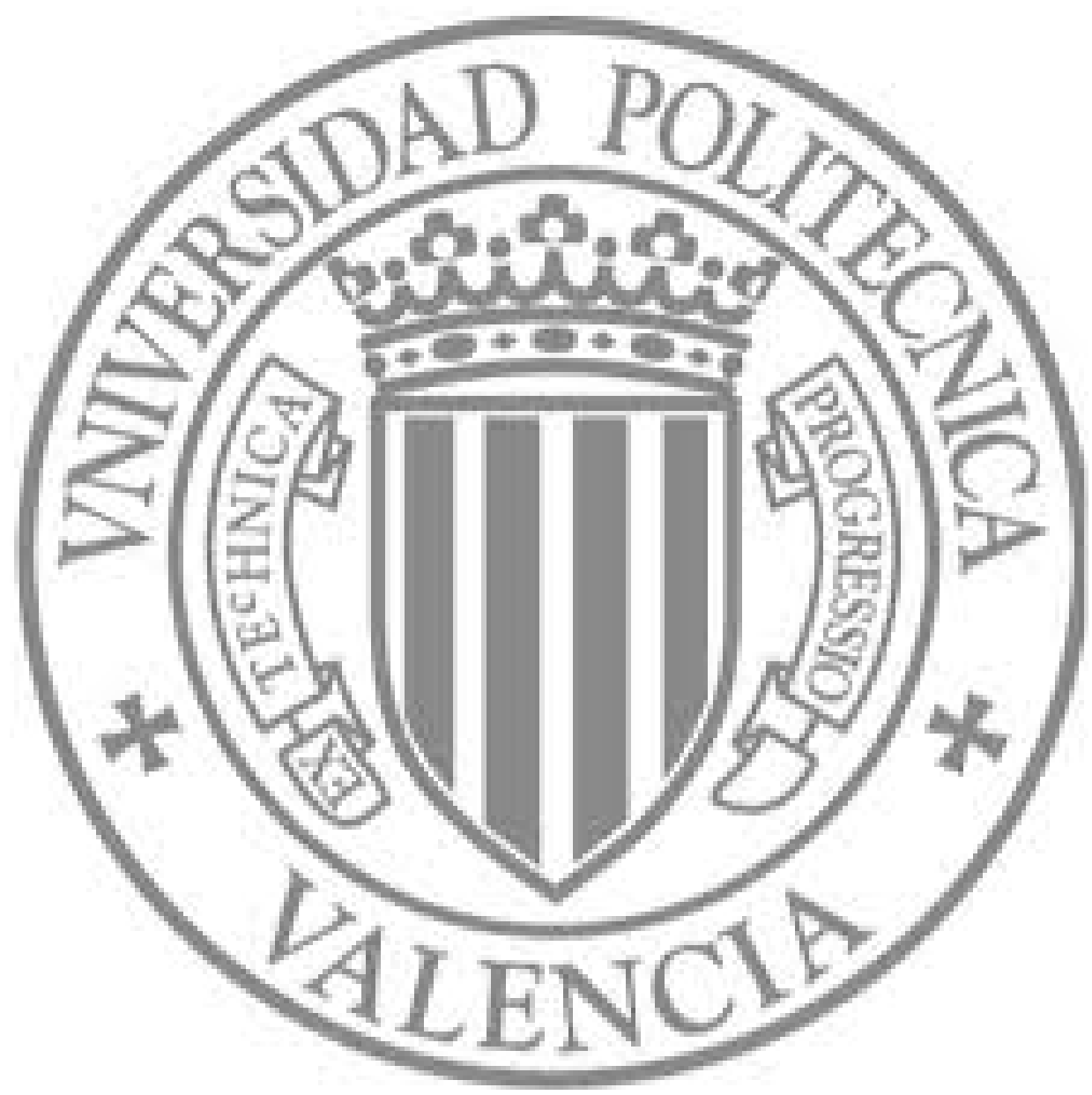

The final publication is available at

http://link.springer.com/article/10.1007\%2Fs11746-012-2171-2

Copyright Springer Verlag (Germany) 


\title{
STUDY OF THE PROPERTIES OF THERMOSET MATERIALS DERIVED FROM EPOXIDIZED SOYBEAN OIL AND PROTEIN FILLERS
}

\author{
Fombuena V*., García-Sanoguera D., Boronat T., Sánchez-Nácher L. and Balart R. \\ Instituto de Tecnología de Materiales (ITM), \\ Universitat Politècnica de València (UPV), \\ Plaza Ferrándiz y Carbonell 1, 03801, Alcoy, Spain \\ e-mail: vifombor@upvnet.upv.es
}

\begin{abstract}
:
Novel biobased thermoset formulations have been prepared by using epoxidized soybean oil (ESBO) with different types of proteins as fillers. In the first part of the study, the effect of the protein type (wheat gluten, soy protein, casein and ovalbumin) on cured ESBO materials has been investigated. Thermal and mechanical properties of biobased materials were characterized by flexural tests, Shore D hardness, Charpy impact tests, Vicat softening temperature (VST) and heat deflection temperature (HDT); in addition a study of morphology of fractured surfaces by scanning electron microscopy (SEM) was carried out. In general terms, the addition of protein-based fillers produces an increase in mechanical and thermal properties. It was found that the higher increment of properties is achieved by ovalbumin. In the second part of the work, the effect of total amount of ovalbumin filler was studied. Biobased thermoset materials from ESBO and 15 wt.\% ovalbumin attained to improve, for example, flexural modulus more than $150 \%$ with regard to the unfilled material; similar evolution was observed for other mechanical properties. Moreover the brittleness of this composition is the minimum of the studied systems. A direct relationship between energy absorption capacity and morphologies of the failure surface were evidenced by SEM.
\end{abstract}

Key words: Polymers, Oilseeds, Seed proteins. 


\section{INTRODUCTION}

Biodegradable and biobased materials are receiving increased attention due to their availability from renewable resources and their environmental advantages in comparison to petroleum-based materials. Depletion of non-renewable resources and dependence on petroleum-based polymers is causing a growing urgency to develop and commercialize new, environmentally friendly biobased polymers [1]. In this context, vegetable oils (VOs) such as linseed oil, soybean oil, castor oil, sunflower, etc. have found important uses in polymer material synthesis [2] .

As raw vegetable oils are not very reactive, they need a chemical modification. The fatty acids in the triglyceride structure, have double bonds, $(\mathrm{C}=\mathrm{C})$, which allows to modify their chemical structure through epoxidation [3]. This method for vegetable oils has been known for many years [4]. Epoxidation is one of the most important functionalization and can be done by chemical [5] or enzymatic oxidation [6] . This process leads to obtaining the corresponding epoxidized vegetable oil (EVO). Functionalized vegetable oils such as epoxidized soybean oil (ESBO), acrylated epoxidized soybean oil (AESO), linseed oil monoglyceride maleate, epoxidized linseed oil (ELO), epoxidized canola oil and epoxidized castor oil, etc. among others have been synthesized to prepare thermoset materials and composites [2, 7-9] .

Epoxidized soybean oil is extremely promising for the feasibility of curing with conventional curing agents, including amines [10-14], carboxylic acid anhydrides [1, 2, 15-20] , carboxylic acids [21, 22], mercaptanes, etc. in presence of tertiary amines in a similar way to conventional petroleum-based epoxy resins. Epoxidized vegetable oils can be cured with cyclic anhydrides to provide thermoset materials with attracting and balanced properties which can be used as matrices for green composites [23, 24] . Curing with cyclic anhydrides provides high glass transition temperature $(\mathrm{Tg})$ values and for this reason, they are widely used as curing agents for epoxies. Among the wide variety of cyclic anhydrides, some of them such as maleic anhydride (MA), phthalic anhydride (PA), tetrahydrophthalic anhydride (THPA), hexahydrophthalic anhydride 
(HHPA) are solid at room temperature and this requires heating at moderate temperatures to obtain a homogeneous mixture with the epoxidized vegetable oil. For this reason, liquid cyclic anhydrides such as methyl hexahydrophthalic anhydride (MHHPA), methyl tetrahydrophthalic anhydride (MTHPA), etc. are preferred from industrial point of view. Methyl-5 norbornene-2,3,dicarboxylic anhydride or nadic methyl anhydride (NMA) is an interesting cross-linking agent, since it is liquid at room temperature, it can easily be mixed with the resin and the final cured network possess a very high heat distortion temperature [25] due to the chemical structure.

However epoxidized soybean oil has some drawbacks; thermoset materials derived from ESBO are characterized by relatively low mechanical performance if compared to conventional epoxies or even if compared to other vegetable oil based thermosets such as those derived from epoxidized linseed oil (ELO). ESBO is characterized by an epoxide equivalent weight (EEW), in the 230 - $240 \mathrm{~g}$ equiv $^{-1}$ range $^{-1}$ while many commercial epoxy resins possess an EEW of about 170-190 $\mathrm{g}$ equiv $^{-1}$. This relatively high EEW of ESBO in comparison to ELO is responsible for flexibility as ESBO possesses less epoxide groups per molecule. Some industrial applications of epoxy resins require good mechanical properties in terms of flexural modulus, hardness, dimensional stability, etc. so that, in order to provide these features, use of fillers is needed $[26,27]$.

In the recent years, with the aim to obtain high renewable content materials, proteins have focused the attention as an alternative to petroleum polymers industry. Proteins can be a viable source of polymers for fibers, molded plastic parts, films, fillers, etc. for a wide variety of products currently supplied by petroleum-based polymers [28] . Proteins can be defined as natural polymers based on polypeptide structures which are able to form three-dimensional structures stabilized mainly by noncovalent interactions. Numerous vegetable and animal proteins such as wheat gluten, soy protein isolate, peanuts proteins, milk proteins (casein), keratin, proteins from eggs (ovalbumin), etc. could be used as potential natural fillers [29] .These 
proteins have good processability, both in the aqueous and melt media, good mechanical properties in films, excellent interaction with various substrates (coatings, adhesives), high resistance to UV, high barrier properties for $\mathrm{O}_{2}$ and $\mathrm{CO}_{2}$ gases, etc. $[30,31]$. All these properties could be transferred to thermoset polymers derived from epoxidized soybean oil when proteins are used as fillers.

Therefore, the main aim of this study is to develop novel thermoset materials derived from epoxidized soybean oil (ESBO) as matrix and different protein-based fillers: wheat gluten, soy protein, ovalbumin and casein. The use of these protein fillers is intended to increase the relatively low mechanical and thermal performance of thermoset materials derived from ESBO cured with cyclic anhydrides.

\section{EXPERIMENTAL}

\subsection{Materials and preparation of samples}

The epoxidized soybean oil (ESBO) was kindly provided byTraquisa S. A. (Barberá del Vallés, Barcelona, Spain). The distribution of fatty acids is in average term as follows: $3-5 \%$ stearic acid, $6-10 \%$ linoleic acid, $8-12 \%$ palmitic acid, $20-26 \%$ oleic acid and $48-57 \%$ linoleic acid. ESBO is characterized by an average molecular weight of $926 \mathrm{~g} \mathrm{~mol}^{-1}$ and contains about $6.6-8.8 \%$ of epoxide oxygen.

The hardener used was a cyclic anhydride: nadic methyl anhydride (NMA). 1methyl imidazole was used as accelerator and glycerol was used to provide hydroxyl groups to initiate the curing reaction. All they were supplied by Sigma Aldrich (Sigma Aldrich Spain, Madrid, Spain)

The wheat gluten (WG) was supplied by Indespan (Indespan, Valencia, Spain). It contained $80 \%$ proteins, $15 \%$ residual starch, $4 \%$ lipid and around $1 \%$ fibers and other impurities on a dry basis. Ovalbumin (OA), casein (CAS) and soy protein (SOY) were food grade proteins supplied by Coralim (Coralim aditivos, Valencia, Spain).

The moisture content of each protein was previously studied. For this, 100 grams of protein, as they are received, are dried at $100^{\circ} \mathrm{C}$ in an oven for 24 hours. The 
moisture content was $6.5,7.3,6.4$ and 8.2 wt. \% for wheat gluten, casein, soy protein and ovalbumin respectively.

The study is divided in two parts; the first part analyzes the results obtained with different proteins (WG, OA, CAS and SOY). These are mixed with the base resin (ESBO) and hardener in a constant amount of $10 \mathrm{wt}$ \% protein filler. In the second experimental part, the amount of protein that best interaction and better thermomechanical results give has been optimized. For this, the results of samples with 5,10 , 15,20 and $30 \%$ wt. are analyzed.

The equivalent epoxide weight to anhydride equivalent weight ratio (EEW:AEW) was set to 1:0.9; the base resin was prepared by mixing the ESBO and MNA at room temperature; then, 2 wt. \% 1-methyl imidazole and 0.8 wt. \% glycerol were hand-mixed. Then, the mixture was mechanically mixed at room temperature with an intensive mixer (Brabender Instruments Co. Germany) at 100 rpm for 20 min. with appropriate amount and type of protein. All amounts of products were weighed in an analytical balance Mettler Toledo AG245 (Barcelona, Spain). After the homogeneous mixing of all components, the mixture was placed in a aluminum mold without cover, and the liquid mixture was subjected to a curing cycle of $1 \mathrm{~h}$ at $90^{\circ} \mathrm{C}+2 \mathrm{~h}$ at $100^{\circ} \mathrm{C}+1 \mathrm{~h}$ at $120^{\circ} \mathrm{C}$. Once the samples were correctly cured, they were stabilized at room temperature for $24 \mathrm{~h}$. After the stabilization, the samples were cut to obtain test samples for different thermal and mechanical characterization.

\subsection{Mechanical and thermal properties.}

Flexural measurements were performed using a electromechanical universal test machine Elib 30 (Ibertest S.A.E, Madrid, Spain) according to ISO 178. The thickness of individual flexural bars was measured before testing and ranged from 3.8 to $4.2 \mathrm{~mm}$. The width of the sample was $10 \mathrm{~mm}$ and the length $80 \mathrm{~mm}$. The extension rate was $5 \mathrm{~mm} \mathrm{~min}^{-1}$. All samples were conditioned for at least $48 \mathrm{~h}$ at standard room temperature and humidity ( $23^{\circ} \mathrm{C}$ and $40 \%$ relative humidity). Each test was repeated at 
least five times and average values were used in data analysis. The flexural modulus (Ef), the maximum resistance $(\mathrm{Rm})$ and the maximum force $(\mathrm{Fm})$ were evaluated.

Shore D hardness was measured with a Shore durometer Model 673-D (J. Bot Instruments, Barcelona, Spain) according to UNE-EN ISO 868. In order to evaluate the dynamic fracture toughness, the Charpy impact values of the samples were measured using a Charpy pendulum (Metrotec S. A., San Sebastian, Spain) with an energy of $1 \mathrm{~J}$, according to ISO 179. Each measure, both in hardness and Impact Test, is expressed as the average value from five duplicates for each product.

The Vicat softening temperature (VST) and the Heat deflection temperature (HDT) of the materials were determined with a Vicat/HDT machine model VHDT 20 (Metrotec S.A., San Sebastian, Spain). The Vicat test was carried out with a total load of $5 \mathrm{~kg}$ and a heating rate of $50{ }^{\circ} \mathrm{C} \mathrm{h}^{-1}$ following the guidelines of ISO 306 standard. By the other hand, HDT was determinate under a load of $296 \mathrm{~g}$ and the temperature rate was elevated of $120^{\circ} \mathrm{C} / \mathrm{h}$, in accordance of normative ISO 75 .

\subsection{Scanning electron microscopy (SEM).}

The fractured surfaces from impact tests were observed with a FEI model Phenom (FEI Company, Eindhoven, The Netherlands) scanning electron microscope at a $5 \mathrm{kV}$ accelerating voltage. Prior to surface observation, samples were coated with gold-palladium alloy in a sputter coater EMITECH mod. SC7620 (Quorum Technologies Ltd., East Sussex, United Kingdom).

\section{RESULTS AND DISCUSSION}

\subsection{Effect of the protein type on performance of ESBO thermoset materials.}

In the first part of the study, the effect of the protein-type filler at a constant load of 10 wt. \% is evaluated. Thereby the protein type is optimized as a function of better interaction between ESBO matrix and filler and better mechanical and thermal 
properties. Fig. 1 shows a bar plot of the flexural modulus in terms of the different type of protein used as filler.

\section{Figure 1}

With the exception of the ESBO with wheat gluten, the flexural modulus obtained is greater than the unfilled material. The increase in flexural modulus is a direct consequence of the restriction of the global cooperative chain movement of ESBO chains by hardener and the protein filler network structure [32] .

The flexural modulus of the unfilled ESBO is $2254 \mathrm{MPa}$. The only addition of 10 wt. \% of soy protein produces an increase of about $740 \mathrm{MPa}$ which represents a percentage increase of $33 \%$. When the protein used as filler is wheat gluten, the flexural modulus is reduced from $2254 \mathrm{MPa}$ (unfilled material) to $638 \mathrm{MPa}$, (percentage decrease of $71 \%$ ). This could be representative for low interaction between wheat gluten protein and the crosslinked net structure derived from ESBO and NMA [33] .The addition of casein substantially improves the flexural modulus of the material up to values close to $4300 \mathrm{MPa}$ ( $91 \%$ increase). Similar results are obtained by using ovalbumin as filler. The flexural modulus is incremented above $4500 \mathrm{MPa}$, a value twice the unfilled material. The results suggest that addition of protein filler can effectively reinforce the ESBO matrix. Thus, by means of $10 \mathrm{wt}$ \% of protein, excepting with wheat gluten, a substantial increment of flexural modulus is attained. Ovalbumin protein is shown as the protein that better results achieve, doubling the flexural modulus of the unfilled material

Following with the thermal and mechanical analysis of the ESBO based thermoset materials, Vicat and HDT temperature are studied. The results are shown in Fig. 2. The addition of a protein filler (10 wt. \%) produces an increase in both VST and HDT values. Once again, the highest Vicat softening temperature (VST) and heat deflection temperature (HDT) values are obtained for ovalbumin. Although all proteins 
are able to achieve an increment in VST and HDT values, ovalbumin attains the maximum values. VST and HDT values are improved more than $30 \%$, and $44 \%$ respectively.

\section{Figure 2}

The results of the Charpy impact test and the Shore D hardness of the unfilled ESBO matrix and ESBO materials with different type of protein fillers are summarized in Fig. 3. Shore D Hardness is improved in all samples. Maximum increase occurs in EA 10\% sample. Mechanical properties are improved in the whole of all samples made with different proteins as fillers, as previously noted with the flexural modulus (excepting WG 10\%). Usually an increase in mechanical properties is reflected in a decrease of ductile properties. To test this, was carried out a Charpy Impact Test. Results obtained show a drop in the toughness of the samples. Samples with protein as filler absorb much less energy, being more fragile. As some author has reported, this is one of the main drawbacks when proteins are used to obtain polymeric materials[34] .However, EA 10\% sample has the smallest reduction in toughness compared with REF $0 \%$. The drop of energy absorption capacity is from $0.79 \mathrm{~J} / \mathrm{cm}^{2}$ to $0.23 \mathrm{~J} / \mathrm{cm}^{2}$.

\section{Figure 3}

To give a plausible explanation for the impact results found herein, the failure surface of the samples were observed by SEM, and SEM images are shown in Fig. 4. The study by SEM allows obtaining two types of morphologies. The first characteristic morphology can be found in the sample of the unfilled ESBO matrix [Fig. 4(a)] and in the sample with $10 \mathrm{wt}$ \% ovalbumin [Fig. 4(e)].This morphology is characterized by a high level of surface roughness. There is a high density of cracks and the advance of 
these, during impact testing is produced in parallel. As it can be seen in the images, the samples have a non-uniform general appearance. This morphology with parallel grooves is typical of a ductile behavior of the samples. These samples absorb more energy during crack growth. With regard to the Charpy impact energy values, both samples are characterized by high impact energies $\left(0.79-0.23 \mathrm{~J} \mathrm{~cm}^{-2}\right)$. The sample that absorbs more energy is the sample with higher roughness (unfilled material). On the other hand, the images corresponding to ESBO matrix with 10 wt. \% soy protein, wheat gluten and casein [Fig. 4(b), Fig. 4(c) and Fig. 4(d)] are characterized by featureless failure surfaces. These three materials have similar failure surfaces and characterized by their smooth appearance. Their fractured surface is very homogeneous, without cracks which is typical of a brittle fracture during impact testing [35]. The quantification of the absorbed impact energy in the Charpy test shows a similar behavior, with values ranging between 0.04 and $0.08 \mathrm{~J} \mathrm{~cm}^{-2}$. Values of impact energies are very small, thus indicating the fragility of the material. These observations suggest that the different type of protein play a critical role in the morphology of the fractured surface in the Charpy impact test. It seems evident that samples with lower values of impact energy have very smooth surfaces. When the value of impact energy is higher, greater is the surface roughness. As the impact energy decreases, the roughness in the failure surface also decreases.

\section{Figure 4}

Therefore, summarizing the first part of the study, the different type of resin plays a substantial role in the properties of ESBO thermoset materials. Ovalbumin appears as the protein with better improved interaction with ESBO matrix, resulting in a considerable improvement of thermal and mechanical properties. Furthermore, as some authors report, moisture content of proteins can influence the mechanical properties obtained. Some authors have reported a clear influence on the mechanical 
properties when the protein contains certain amount of water $[32,36]$. In the same way, ovalbumin is the protein with more moisture content, as we can see in Table 1 and it is the protein that provides a greater improvement of the mechanical and thermal properties.

\subsection{The effect of the amount of protein filler on ESBO thermoset materials.}

After selecting the protein that gives an overall improvement on thermomechanical properties, we proceed with the study of the influence of the total amount of protein filler on mechanical and thermal performance of ESBO based thermoset materials. First, the results of the flexural modulus obtained in the flexural test, are shown in the Fig. 5.

\section{Figure 5}

As it can be observed in Fig. 5, we can detect a maximum value at an ovalbumin content of $15 \mathrm{wt}$. \% The tendency is highlighted in order to increase the flexural modulus of the samples as the percentage of ovalbumin filler is increased, up to 15 wt. \%. For this ovalbumin content, an increment from $2254 \mathrm{MPa}$ (unfilled material) up to $5640 \mathrm{MPa}$ is observed. This represents a percentage increase of about $150 \%$. The second conclusion that can be extracted from Fig. 5, is that an amount greater than 15 wt. \% ovalbumin, produces a decrease in mechanical properties as it is evident from flexural modulus values for ESBO materials with 20 and 30 wt. \% ovalbumin. The results suggest that addition of ovalbumin protein as filler can effectively reinforce ESBO thermoset materials up to a maximum content of $15 \mathrm{wt} . \%$.

According to some authors, the increase in mechanical properties by the addition of protein filler in ESBO matrix resin, can be attributed to strong intra- and intermolecular interactions, such as hydrogen bonding, dipole-dipole, charge-charge 
and hydrophobic interactions between polar and non-polar side chains, which restrict segment rotation and molecular mobility $[37,38]$.

However, the decrease in flexural modulus over $15 \mathrm{wt}$ \% can be attributed to a weak interfacial bond between the filler and the matrix. We can think that there is an optimum filler amount that can be dispersed in the ESBO matrix. If this ratio is exceeded, then the filler is not able to establish maximum interaction with ESBO-NMA crosslinked structure thus leading to stress concentration which is responsible for a decrease in mechanical performance [39] . In conclusion, adding an amount of more than 15 wt. \% ovalbumin protein, the ratio between matrix of ESBO resin and filler of proteins is out of adjustment, there being too much filler on the matrix resin, resulting in a low interaction.

Fig. 6, shows the evolution of the VST and HDT values, compared to the unfilled ESBO material. The same trend as in flexural modulus can be observed for VST and HDT values. The maximum values are obtained for ESBO with 15 wt. \% ovalbumin protein. For a sample with this percentage of ovalbumin, VST and HDT values are increased more than $60 \%$ and $62 \%$ respectively. Greater amount of protein does not increase the thermal-mechanical properties, studied by VST and HDT.

\section{Figure 6}

Following with the study of the mechanical properties of the ESBO thermoset polymers, Fig. 7 shows experimental results for Charpy impact test and Shore D hardness in terms of amount of protein. It can be seen clearly, a decrease in the absorbed energy in all samples with protein filler if compared to the unfilled material. The same trend was observed in the first part of the study. However the sample with 15 wt. \% ovalbumin has the smallest reduction in toughness. This sample only reduces its tenacity in a $52 \%$. Beyond this value, the impact energy declined until values close to $0.1 \mathrm{~J} \mathrm{~cm}^{-2}$ for materials with $20 \mathrm{wt}$ \% and $30 \mathrm{wt}$ \% ovalbumin. On the other hand, the 
hardness is increased with the addition of ovalbumin. The obtained values attain a maximum at a weight percentage of $15 \%$. This increment represents an improvement of the $16.5 \%$ in the hardness property.

Figure 7

Finally the results obtained with the Charpy impact test are related with the microstructure observed with SEM analysis. Fig. 8 shows the SEM images for ESBONMA materials with different weight percentages of ovalbumin. As it has been described previously, the SEM analysis of the fractured surfaces is directly related to the results obtained in the Charpy impact test. The sample with highest energy absorption is characterized by a high roughness surface (unfilled ESBO matrix). This sample shows high roughness surface and high heterogeneity [Fig. 8(a)]. In contrast, fractured surfaces of ESBO materials with different amounts of ovalbumin protein exhibited a much less rougher surface. This is in accordance with the results of Charpy impact test. Although all fractured surfaces with ovalbumin are more uniform, smoother surface than unfilled ESBO matrix, it can be observed a gradual increase in roughness surface, as the total amount of ovalbumin increases up to 15 wt. \% [Fig. 8 (b), (c) and (d)]. Sample with 15 wt. \% ovalbumin reveals a steep topography, generated by the growth of microcracks, which require high energy absorption for their formation. Microcracks density is higher. In addition, it seems to be that the microcracks starts in the grains of cured ovalbumin, because there is the possibility that has a lower modulus of rupture compared with the ESBO matrix. The uniformity of the dispersed particles causes crack growth from ovalbumin particles to find the ESBO matrix, which acts as center of dissipation of mechanical energy and offers the maximum in the impact test value [35]. When the ESBO matrix can't absorb more energy, it breaks, thus resulting in the grooves on the surface of the matrix [Fig. 8(d)]. If the total amount of ovalbumin is increased, a decrease in the absorption energy is registered. Samples 
with 20 wt. \% and 30 wt. \% ovalbumin, showed a smoother surface and more homogeneous [Fig. 8(e) and (f)]. Conceivably there are too much ovalbumin, resulting in too large aggregates, giving a poor interface matrix ESBO-ovalbumin, thus leading to making brittle materials.

\section{Figure 8}

\section{CONCLUSIONS}

Novel thermoset materials based on epoxidized soybean oil (ESBO) and NMA as a hardener were prepared with proteins as fillers. Flexural modulus, VST and HDT, Shore D hardness and Charpy impact test are improved by the addition of $10 \mathrm{wt}$. \% of different proteins such as ovalbumin, soy protein and casein. Therefore, the addition of proteins in an ESBO matrix is shown as a simple, economic and environmentally friendly method to increase the mechanical and thermal properties of ESBO-based thermoset materials. Ovalbumin has been is shown as the most effective protein to improve both thermal and mechanical properties. With the addition of 10 wt. \% ovalbumin, the flexural modulus is increased above $100 \%$, thus achieving modulus greater than $4500 \mathrm{MPa}$. The energy absorption capacity is the only parameter that decreases when the proteins are incorporated. However, ovalbumin shows the minimum decrease in the energy absorption capacity. It has been shown the effect of the total content on ovalbumin protein on ESBO matrix and it has been concluded that 15 wt. \% ovalbumin is the optimum amount of protein to provide an increase in mechanical and thermal performance of ESBO based thermoset materials. With this ovalbumin content, increments of $150 \%$ on flexural modulus, $60 \%$ on VST, $62 \%$ on HDT temperature and $16.5 \%$ on Shore D hardness can be achieved. On the other hand, the fragility of ESBO with 15 wt. \% ovalbumin is only a $50 \%$ lower respect the unfilled material. SEM analysis shows a direct relationship between morphology of the fractured surface from Charpy impact test. An increment of the energy absorption 
capacity, show an abrupt and rough surface. Therefore the addition of 15 wt. \% ovalbumin, allows to obtain environmentally friendly materials with balanced mechanical and thermal properties thus contributing to a sustainable development.

\section{ACKNOWLEDGEMENTS}

This work is a part of the project IPT-310000-2010-037,"ECOTEXCOMP: Research and development of textile structures useful as reinforcement of composite materials with marked ecological character" funded by the "Ministerio de Ciencia e Innovacion", with an aid of 189540.20 euros, within the "Plan Nacional de Investigación Científica, Desarrollo e Innovación Tecnológica 2008-2011" and funded by the European Union through FEDER funds, Technology Fund 2007-2013, Operational Programme on $\mathrm{R}+\mathrm{D}+\mathrm{i}$ for and on behalf of the companies." Also, Generalitat Valenciana ACOMP/2012/087 is acknowledged for financial support. 


\section{References}

1. Miyagawa H, Mohanty AK, Drzal LT,Misra M (2005) Nanocomposites from biobased epoxy and single-wall carbon nanotubes: synthesis, and mechanical and thermophysical properties evaluation. Nanotechnology 16:118-124.

2. Boquillon N,Fringant C (2000) Polymer networks derived from curing of epoxidised linseed oil: influence of different catalysts and anhydride hardeners. Polymer 41:8603-8613.

3. Samper MD, Fombuena V, Boronat T, García-Sanoguera D,Balart R (2012) Thermal and Mechanical Characterization of Epoxy Resins (ELO and ESO) Cured with Anhidrides. Journal of American Oil Chemists Society 1-8.

4. La Scala J,Wool RP (2002) Effect of FA composition on epoxidation kinetics of TAG. Journal of the American Oil Chemists Society 79:373-378.

5. Park SJ, Jin FL,Lee JR (2004) Synthesis and thermal properties of epoxidized vegetable oil. Macromolecular Rapid Communications 25:724-727.

6. Rüsch Gen Klaas M,Warwel S (1999) Complete and partial epoxidation of plant oils by lipasecatalyzed perhydrolysis. Ind Crops Prod 9:125-32.

7. Boquillon N, Elbez G,Schonfeld U (2004) Properties of wheat straw particleboards bonded with different types of resin. Journal of Wood Science 50:230-235.

8. Chakrapani S,Crivello JV (1998) Synthesis and photoinitiated cationic polymerization of epoxidized castor oil and its derivatives. Journal of Macromolecular Science-Pure and Applied Chemistry A35:1-20.

9. $\quad$ Espinosa-Perez J, Wiesenborn DP, Tostenson K, Ulven CA,Tatlari M (2007) Preparation and partial characterization of canola-based epoxy resins for bio-based plastic composites. Annual International Meeting 076079: .

10. Czub P (2006) Application of modified natural oils as reactive diluents for epoxy resins. Macromolecular Symposia 242:60-64.

11. Liu ZS, Erhan SZ,Calvert PD (2007) Solid freeform fabrication of epoxidized soybean oil/epoxy composite with bis or polyalkyleneamine curing agents. Composites Part aApplied Science and Manufacturing 38:87-93.

12. Miyagawa H, Mohanty AK, Misra M,Drzal LT (2004) Thermo-physical and impact properties of epoxy containing epoxidized linseed oil, 2(a) - Amine-cured epoxy. Macromolecular Materials and Engineering 289:636-641.

13. Montero de Espinosa L, Ronda JC, Galià M,Cádiz V (2008) A new enone-containing triglyceride derivative as precursor of thermosets from renewable resources. J. Polym. Sci. Part A: Polym. Chem. 46:6843-6850.

14. Zhu J, Chandrashekhara K, Flanigan V,Kapila S (2004) Curing and mechanical characterization of a soy-based epoxy resin system. Journal of Applied Polymer Science 91:3513-3518.

15. Gerbase AE, Petzhold CL,Costa APO (2002) Dynamic mechanical and thermal behavior of epoxy resins based on soybean oil. Journal of the American Oil Chemists Society 79:797-802.

16. Martini DdS, Braga BA,Samios D (2009) On the curing of linseed oil epoxidized methyl esters with different cyclic dicarboxylic anhydrides. Polymer 50:2919-2925.

17. Miyagawa H, Mohanty AK, Burgueno R, Drzal LT,Misra M (2006) Development of biobased unsaturated polyester containing functionalized linseed oil. Industrial \& Engineering Chemistry Research 45:1014-1018.

18. Reiznautt QB, Garcia ITS,Samios D (2009) Oligoesters and polyesters produced by the curing of sunflower oil epoxidized biodiesel with cis-cyclohexane dicarboxylic anhydride: Synthesis and characterization. Materials Science \& Engineering CMaterials for Biological Applications 29:2302-2311. 
19. Sharma BK, Liu Z, Adhvaryu A,Erhan SZ (2008) One-pot synthesis of chemically modified vegetable oils. Journal of Agricultural and Food Chemistry 56:3049-3056.

20. Tran P, Graiver D,Narayan R (2006) Biocomposites synthesized from chemically modified soy oil and biofibers. Journal of Applied Polymer Science 102:69-75.

21. Dogan E,Kuesefoglu S (2008) Synthesis and in situ foaming of biodegradable malonic acid ESO polymers. Journal of Applied Polymer Science 110:1129-1135.

22. Shogren RL, Petrovic Z, Liu ZS, Erhan SZ (2004) Biodegradation behavior of some vegetable oil-based polymers. Journal of Polymers and the Environment 12:173-178.

23. Boquillon N (2006) Use of an epoxidized oil-based resin as matrix in vegetable fibersreinforced composites. Journal of Applied Polymer Science 101:4037-4043.

24. Matejka L, Lovy J, Pokorny S, Bouchal K,Dusek K (1983) Curing epoxy-resins with anhydrides - model reactions and reaction-mechanism. Journal of Polymer Science Part a-Polymer Chemistry 21:2873-2885.

25. Alonso MV, Oliet M, Garcia J, Rodriguez F,Echeverria J (2006) Gelation and isoconversional kinetic analysis of lignin-phenol-formaldehyde resol resins cure. Chemical Engineering Journal 122:159-166.

26. Jones RF, In Guide to Short Fiber Reinforced Plastics, ed. H.G. Publications. Vol. Chapter 1. 1998, Cincinnati.

27. Pfister DP, Baker RJ, Henna HP, Lu Y,Larock CR (2008) Preparation and properties of tung oil-baed composites using spent germ as a natural filler. Journal of Applied Polymer Science 108:3618-3625.

28. Sharma S, Fabrication and characterization of polymer blends and composites derived from biopolymers, in Philosophy Materials Science and Engineering. 2008, Graduate School of Clemson University: Clemson.

29. Cuq B, Contard N,Guilbert S (1998) Proteins as agricultural polymers for packaging production. American association of cereal chemists 75:1-9.

30. De Graaf LA,Kolster $\mathrm{P}$, Industrial proteins as green alternative for "petro" polymers: potentials and limitations, in Macromolecular Symposium 1998.

31. Lim LT, Mine Y,Tung MA (1998) Transglutaminase cross-linked egg white protein films: tensile properties and oxygen permeability. . Journal of Agricultural and Food Chemistry 46:4022-4029.

32. Chen F,Zhang JW (2009) A new approach for morphology control of poly(butylene adipate-co-terephthalate) and soy protein blends. Polymer 50:3770-3777.

33. Mohamed A, Finkenstadt VL, Gordon SH,Palmquist DE (2010) Thermal and Mechanical Properties of Compression-Molded pMDI-Reinforced PCL/Gluten Composites. Journal of Applied Polymer Science 118:2778-2790.

34. Wang S, Sue HJ,Jane J (1996) Effects of polyhydric alcohols on the mechanical properties of soy protein plastics. Journal of Macromolecular Science-Pure and Applied Chemistry A33:557-569.

35. Altuna FI, Esposito LH, Ruseckaite RA,Stefani PM (2011) Thermal and Mechanical Properties of Anhydride-Cured Epoxy Resins with Different Contents of Biobased Epoxidized Soybean Oil. Journal of Applied Polymer Science 120:789-798.

36. Sailaja RRN, Girija BG, Madras G,Balasubramanian N (2008) Effect of compatibilization on mechanical and thermal properties of polypropylene-soy flour composites. Journal of Materials Science 43:64-7.

37. Jin H, Zhang L,Chen F (2003) Effects of lignin as a filler on properties of soy protein plastics. I. Lignosulfonate. journal of Applied Polymer Science 88:3284-3290.

38. Sue HJ, Wang S,Jane J (1997) Morphology and Mechanical Behaviour of Engineering Soy Plastics. . Journal polymer 38:5035.

39. Wazzan AA, Al-Turaif HA,Abdelkader AF ( 2006) Influence of Submicron TiO2 Particles on the Mechanical Properties and Fracture Characteristics of Cured Epoxy Resin. Polymer-Plastics Technology and Engineering, 45:1155-1161. 


\section{Figure legends}

Figure 1.- Comparative bar plot of the flexural modulus of the reference sample and samples with 10 wt. \% of different proteins.

Figure 2.- Comparative bar plot of the VST and HDT values of the reference sample and samples with $10 \%$ wt of different proteins.

Figure 3.- Comparative bar plot of the Shore D hardness and Charpy impact energy of the reference sample and samples with $10 \%$ wt of different proteins.

Figure 4.- SEM images (magnification $=1000 x$ ) of the fractured samples from impact tests of (a) unfilled ESBO , (b) ESBO + 10 wt.\% soy protein (c) ESBO + 10 wt.\% wheat gluten, (d) ESBO + 10 wt.\% casein and (e) ESBO + 10 wt.\% ovalbumin

Figure 5.- Plot evolution of the flexural modulus of the reference sample and samples with different amounts of ovalbumin protein.

Figure 6.- Plot evolution of the VST and HDT values of the reference sample and samples with different amounts of ovalbumin protein.

Figure 7.- Hardness Shore D and Charpy Impact Test of the reference sample and samples with different amounts of EA protein.

Figure 8.- SEM images (magnification $=1000 \mathrm{x}$ ) of the fractured samples from impact tests of (a) unfilled ESBO (b) ESBO + 5 wt.\% ovalbumin (c) ESBO + 10 wt.\% ovalbumin (d) ESBO + 15 wt.\% ovalbumin (e) ESBO + 20 wt.\% ovalbumin and (f) $\mathrm{ESBO}+30$ wt. \% ovalbumin 
Figure 1

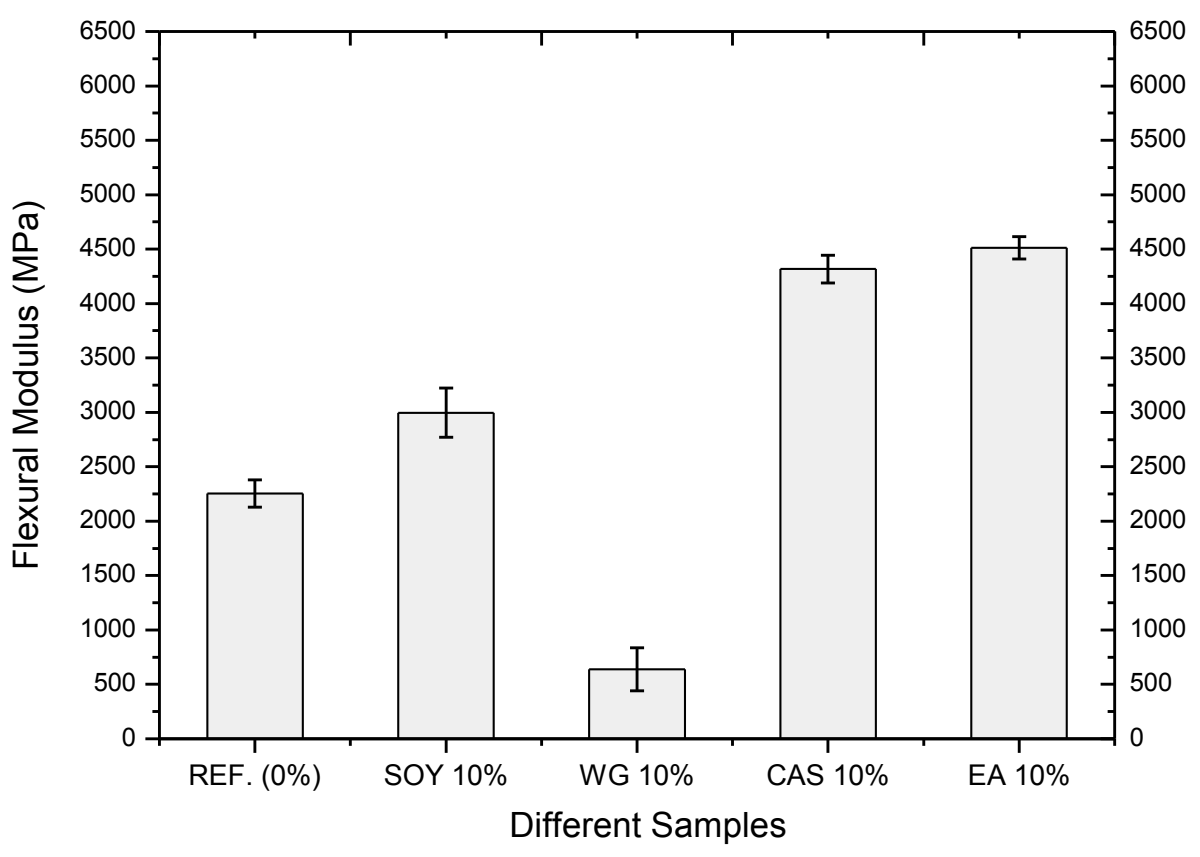


Figure 2

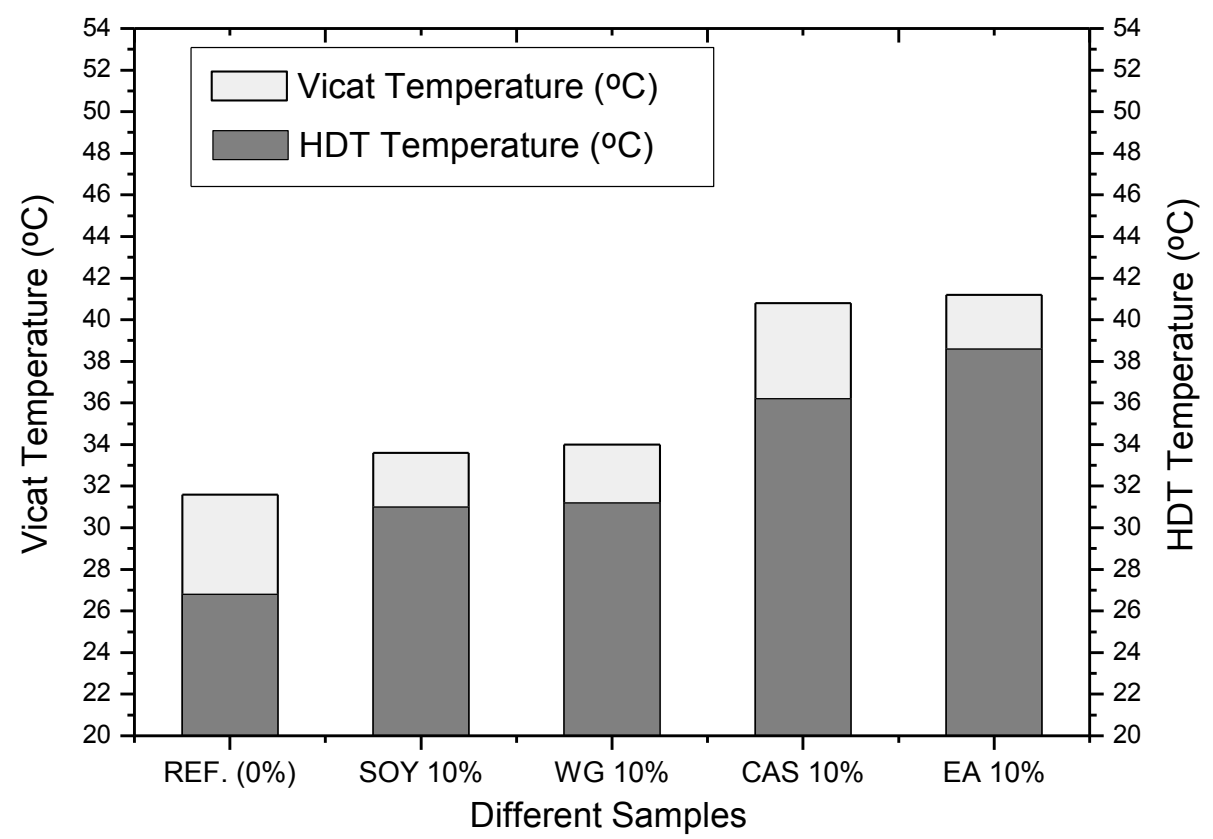


Figure 3

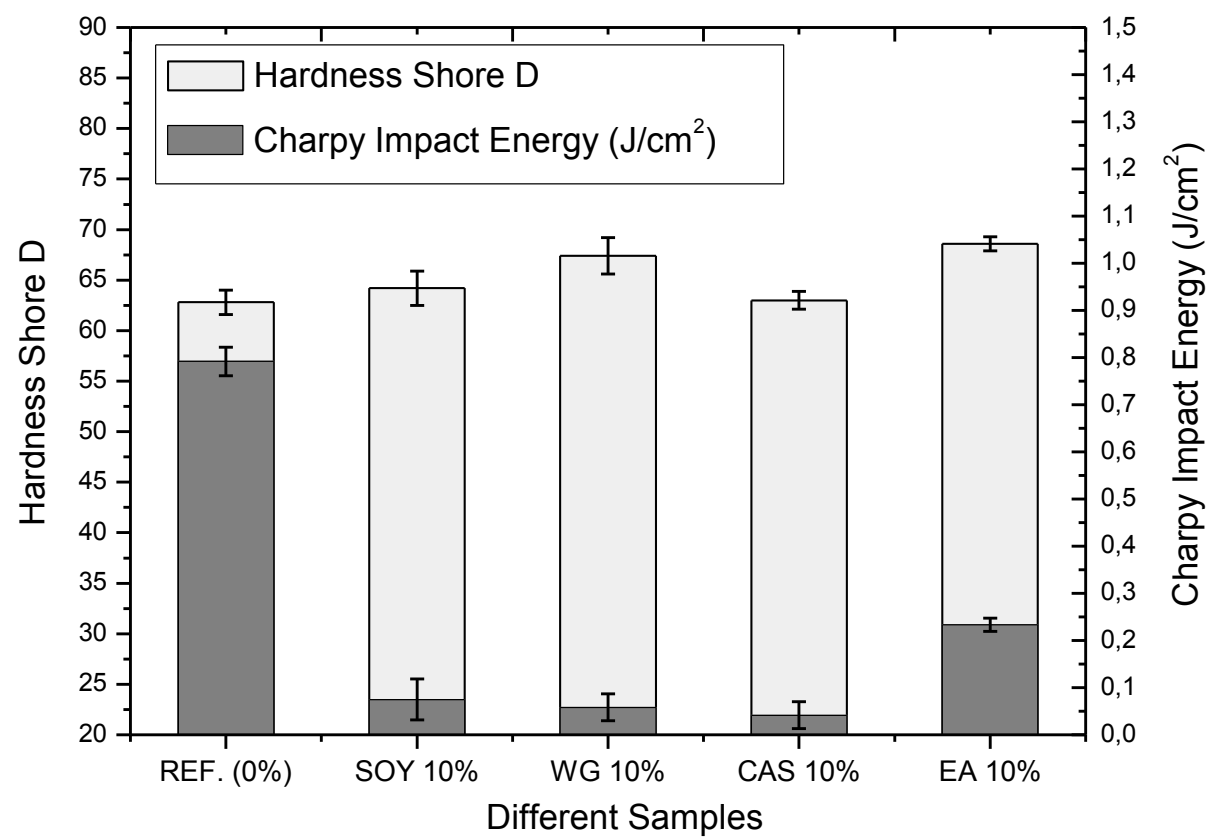


Figure 4
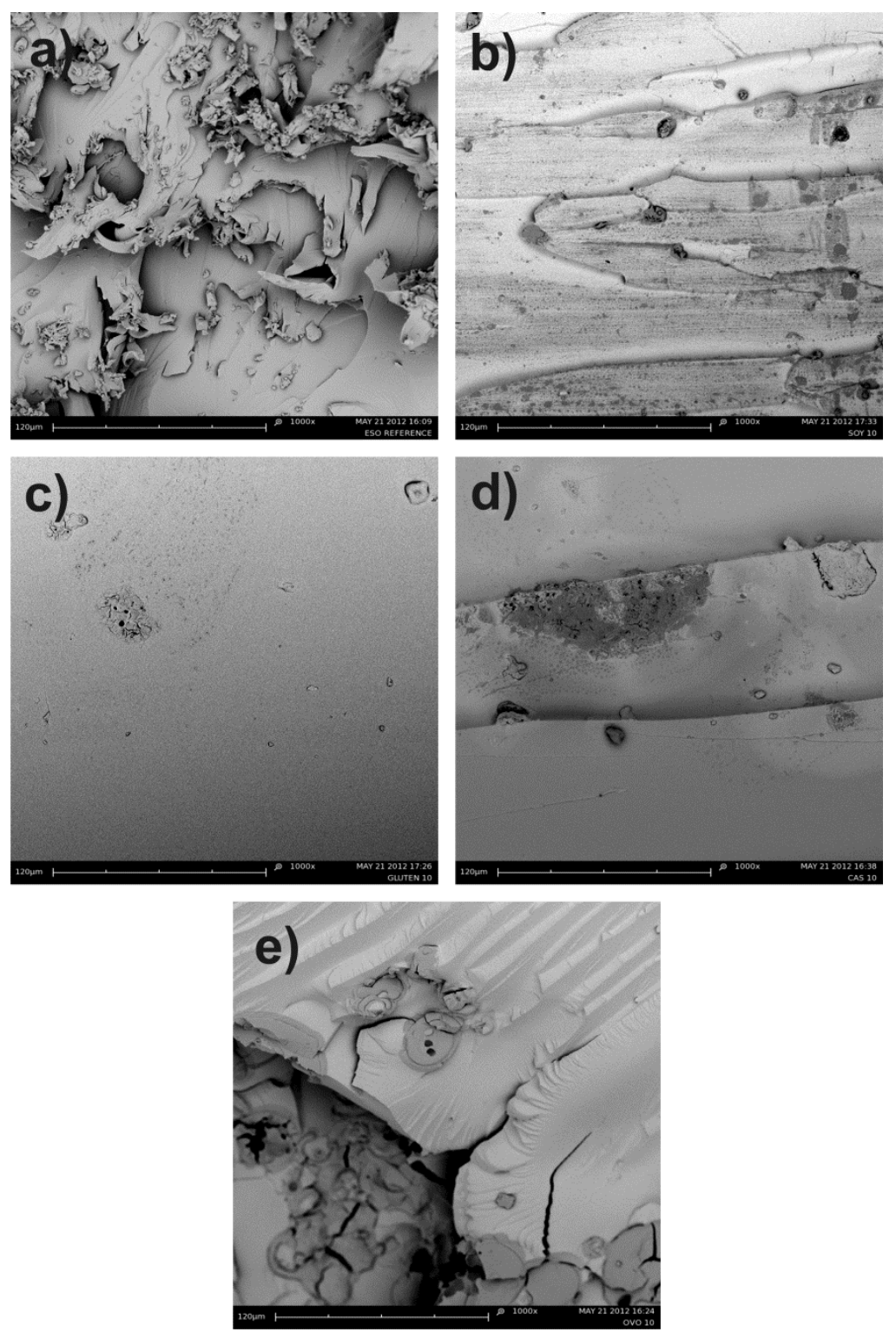
Figure 5

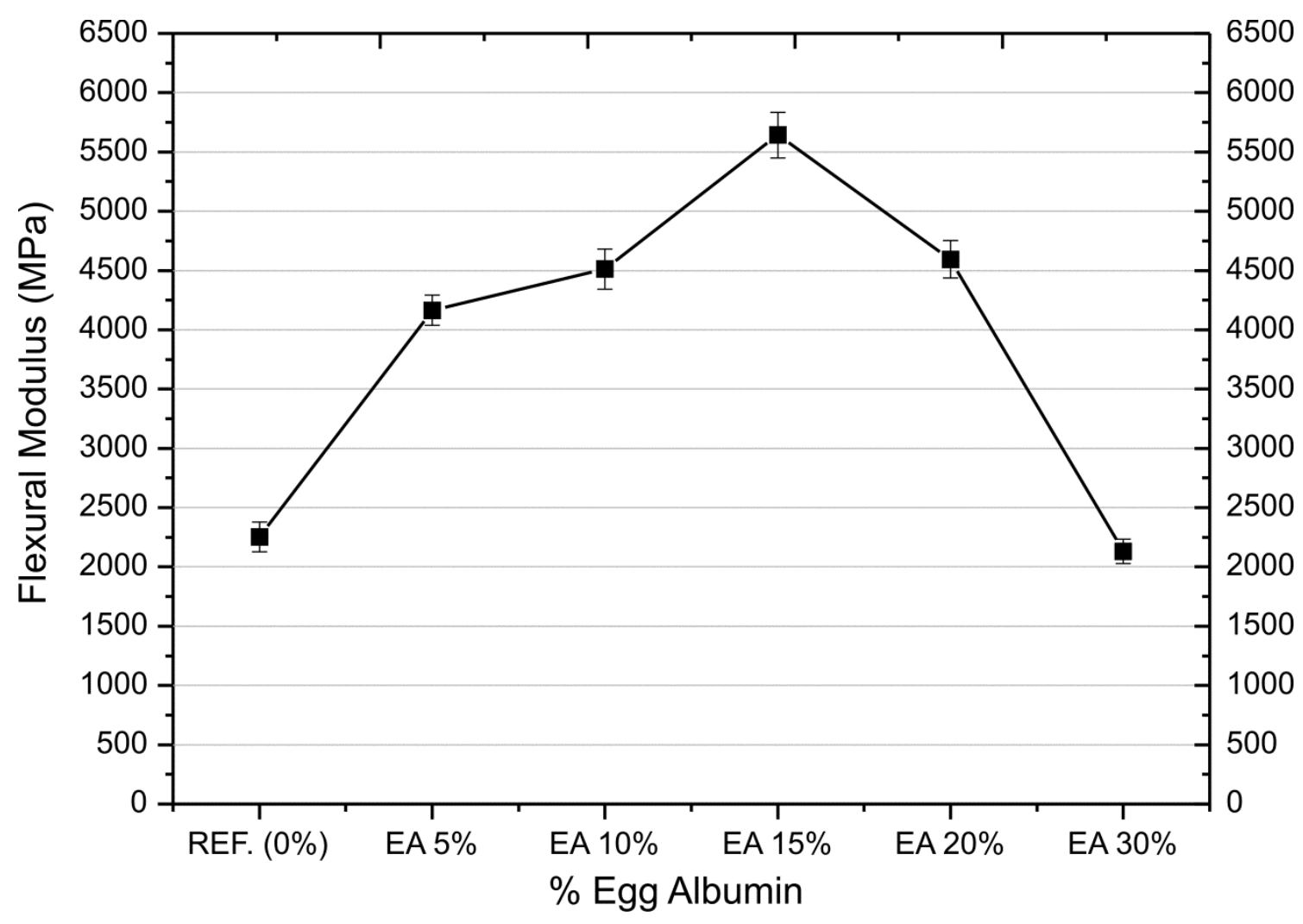


Figure 6

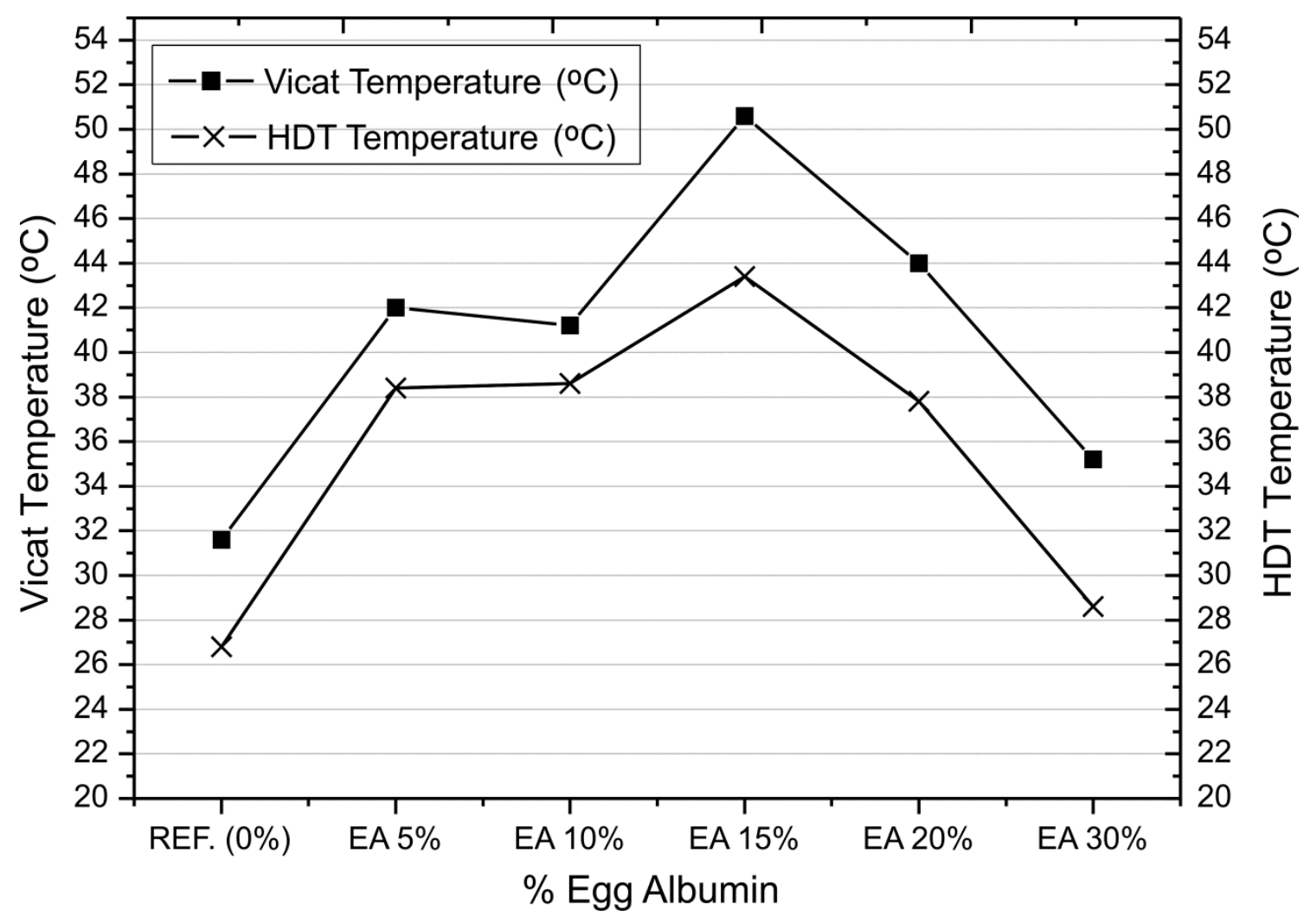


Figure 7

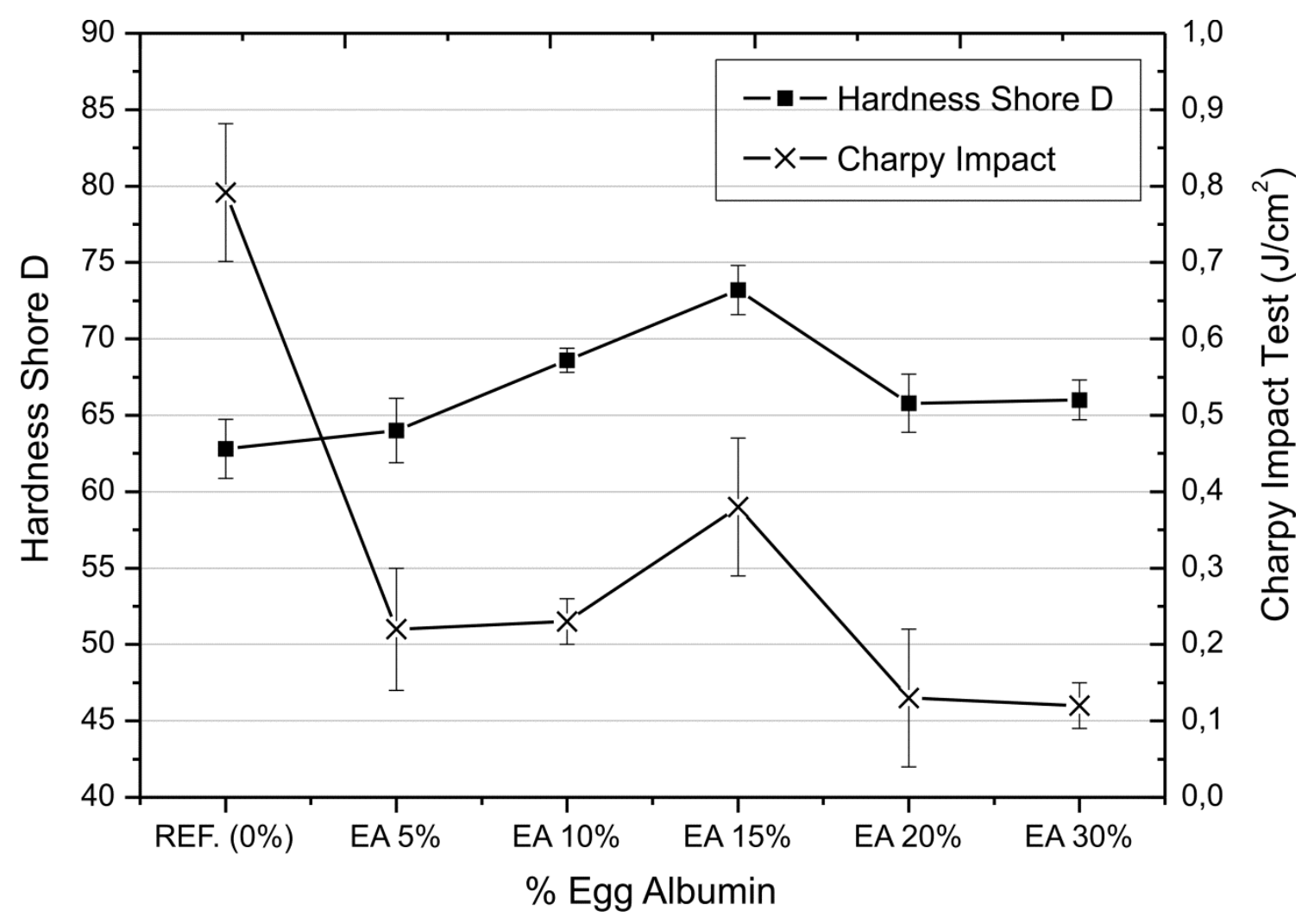


Figure 8
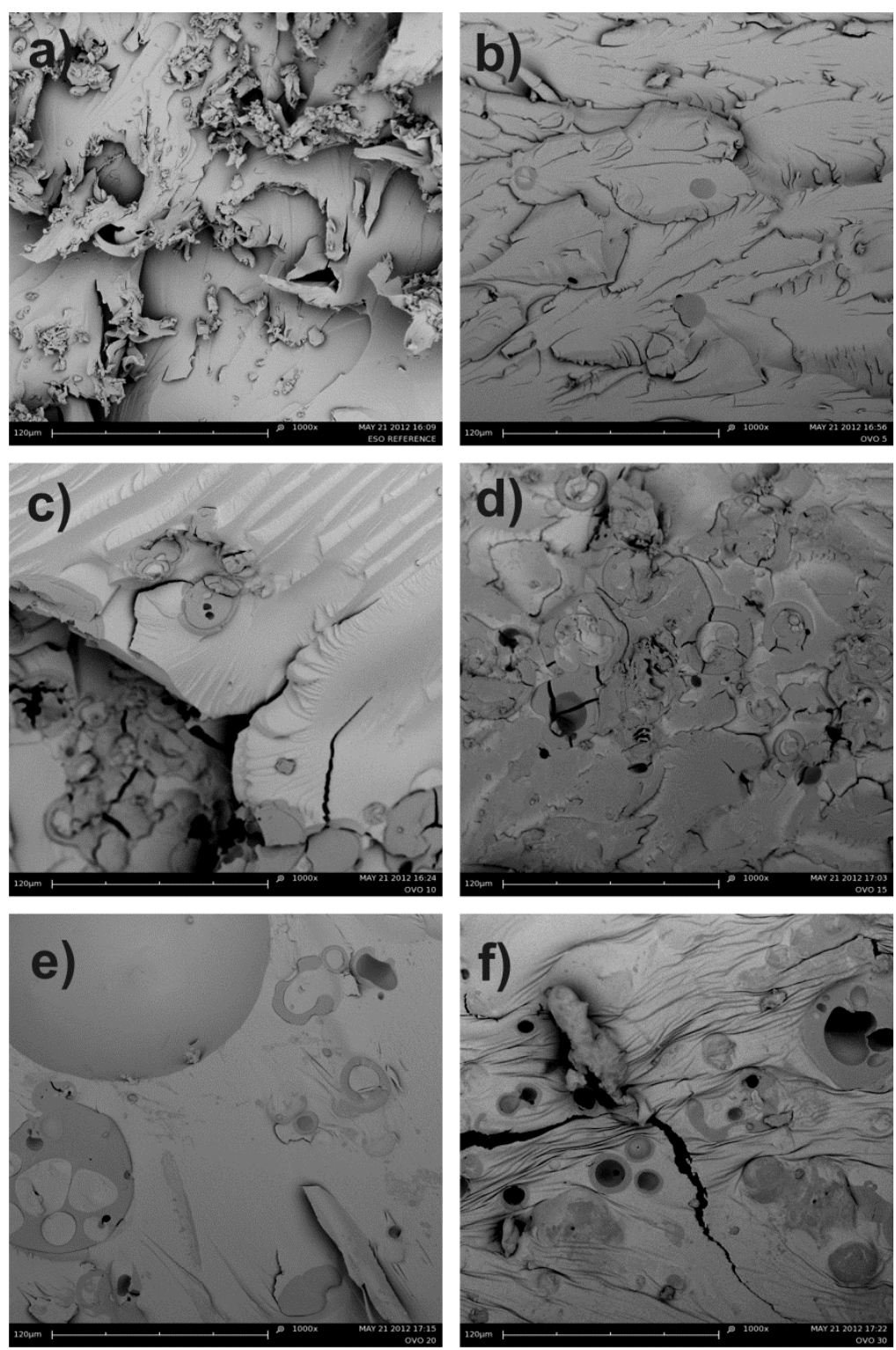